\title{
PEMBUATAN NANOPARTIKEL PERAK YANG RAMAH LINGKUNGAN BESERTA APLIKASINYA UNTUK MENDETEKSI ION MERKURI SECARA CITRA DIGITAL
}

\author{
M. LUTFI FirdAus ${ }^{1 *}$, HAdi APRIYOANDA ${ }^{1}$, ElVINAWATI $^{1}$, EKO SWISTORO ${ }^{1}$, DAN AGUS \\ SUNDARYONO ${ }^{1}$ \\ ${ }^{1}$ Program Pascasarjana Pendidikan IPA, Universitas Bengkulu \\ Jl. WR Supratman Bengkulu 38371 \\ *alamat email korespondensi: lutfi@ unib.ac.id
}

\begin{tabular}{l} 
Informasi Artikel \\
\hline Riwayat Naskah : \\
Diterima pada 23 \\
November 2019 \\
Diterima setelah \\
direvisi pada 26 \\
Desember 2019 \\
Diterbitkan pada 30 \\
Desember 2019
\end{tabular}

Kata Kunci:

Nanopartikel perak; biosintesis; merkuri; citra digital, kolorimetri.

Keywords: Silver nanoparticles; biosynthesis; mercury; digital image, colorimetry.

\begin{abstract}
Abstrak/Abstract
Dewasa ini, nanopartikel mendapatkan perhatian istimewa di kalangan para peneliti termasuk pemerhati lingkungan karena nanopartikel memiliki luas permukaan yang sangat besar sehingga bisa dimanfaatkan lebih lanjut untuk berbagai keperluan. Penelitian ini bertujuan untuk membuat nanopartikel perak secara biosintesis menggunakan ekstrak buah anggur beserta aplikasinya sebagai pereaksi dalam mendeteksi logam berat berbahaya, khususnya merkuri (II). Buah anggur diekstraksi menggunakan air pada suhu $80^{\circ} \mathrm{C}$. Setelah dicampur dengan prekursor perak nitrat, reaksi pembentukan nanopartikel perak dipercepat dengan memanfaatkan sinar matahari sebagai energi panas alami. Nanopartikel perak yang terbentuk memiliki puncak absorbansi pada panjang gelombang maksimum $420 \mathrm{~nm}$, dan selektif terhadap ion merkuri (II), yang ditandai dengan berubahnya warna nanopartikel perak tersebut dari coklat kekuningan menjadi bening. Selanjutnya, kamera digital dimanfaatkan untuk menganalisis konsentrasi ion merkuri di dalam sampel. Keakuratan metode citra digital ditentukan dengan membandingkan hasil pengukurannya terhadap metode Spektrofotometri UV-Vis. Secara umum, metode citra digital dengan nanopartikel perak sebagai reagen deteksi ion merkuri dapat digunakan dengan kinerja mumpuni. Konsentrasi ion $\mathrm{Hg}$ (II) dari sampel lingkungan yang dianalisis menggunakan metode yang dikembangkan ini berada di bawah ambang batas yang diperbolehkan oleh Permenkes RI No. 492 tahun 2010, sehingga air lingkungan yang dianalisis masih layak dipergunakan untuk kebutuhan rumah tangga.
\end{abstract}

\section{PENDAHULUAN}

Merkuri merupakan salah satu zat kimia paling toksik yang ada di permukaan bumi [1]. Secara alami, merkuri terdapat dalam jumlah kecil di udara, air, dan tanah. Merkuri dihasilkan dari aktivitas gunung berapi, pelapukan batuan dan aktivitas manusia [2, 3]. Manusia modern saat ini secara aktif mengekstrak merkuri dari perut bumi untuk berbagai keperluan, seperti penambangan emas, pembangkit listrik dengan bahan bakar batu bara dan hasil dari industri lainnya. Proses terpaparnya manusia oleh merkuri bisa melalui terhisapnya uap merkuri, masuk melalui mulut, injeksi dan adsorpsi melalui kulit. Manusia yang terpapar merkuri akan terganggu sistem syarafnya, ginjal, kulit, mata, saluran pencernaan dan sistem imunitas-nya $[4,5]$.

Di alam, merkuri berada dalam 3 bentuk yaitu merkuri murni, senyawa merkuri anorganik 
dan senyawa merkuri organik. Merkuri organik dalam bentuk metil merkuri $\left(\mathrm{CH}_{3} \mathrm{Hg}\right)$ memiliki angka $\mathrm{LD}_{50}$ atau dosis mematikan sebesar $1 \mathrm{mg} / \mathrm{kg}$, artinya manusia yang terpapar sedikit saja metil merkuri sudah bisa terancam nyawanya [6]. Metil merkuri ini bisa dihasilkan dari senyawa merkuri lain oleh mikroorganisme yang ada di lingkungan. Metil merkuri bersifat bioakumulasi, sehingga ikan besar (seperti tuna) yang makanannya ikan kecil akan memiliki kandungan merkuri yang lebih besar karena hasil akumulasi tersebut. Oleh karena itu, tidak dianjurkan memakan ikan dari perairan yang tercemar oleh merkuri [7-9].

Oleh karena tingginya bahaya merkuri tersebut, maka monitoring konsentrasi merkuri di lingkungan sangat lah penting. Pada saat ini, analisis kuantitatif merkuri biasanya dilakukan menggunakan alat atau instrumen yang ukurannya besar sehingga tidak bisa dibawa ke lapangan, seperti voltameter, spektrometer serapan atom (SSA), Inductively Coupled Plasma-Atomic Emission Spectrometer (ICP-AES), dsb. [9-11]. Selain itu, harga alat tersebut juga sangat mahal, sehingga kepemilikannya sangat terbatas. Penelitian ini bertujuan untuk membuat metode analisis kuantitatif ion merkuri menggunakan nanopartikel perak (NPP) sebagai pereaksinya dan metode kolorimetri citra digital sebagai metode deteksinya untuk menggantikan instrument yang mahal.

\section{EKSPERIMEN}

\section{Material}

Zat kimia yang dipakai pada penelitian ini yaitu: $\quad \mathrm{AgNO}_{3}, \quad \mathrm{Al}\left(\mathrm{NO}_{3}\right)_{3} .9 \mathrm{H}_{2} \mathrm{O}, \quad \mathrm{CaCl}_{2}$, $\mathrm{Cr}\left(\mathrm{NO}_{3}\right)_{3} .9 \mathrm{H}_{2} \mathrm{O}, \quad \mathrm{Co}\left(\mathrm{NO}_{3}\right)_{2} .6 \mathrm{H}_{2} \mathrm{O}, \mathrm{CuSO}_{4} .5 \mathrm{H}_{2} \mathrm{O}$, $\mathrm{FeCl}_{2} \cdot 4 \mathrm{H}_{2} \mathrm{O}, \quad \mathrm{FeCl}_{3} \cdot 6 \mathrm{H}_{2} \mathrm{O}, \quad \mathrm{HgCl}_{2}, \quad \mathrm{KCl}$, $\mathrm{MgCl}_{2} \cdot 6 \mathrm{H}_{2} \mathrm{O}, \mathrm{MnSO}_{4} \cdot \mathrm{H}_{2} \mathrm{O}, \mathrm{NaCl}, \mathrm{NiSO}_{4} \cdot 6 \mathrm{H}_{2} \mathrm{O}$, $\mathrm{PbNO}_{3}, \mathrm{ZnCl}_{2}$, dan $\mathrm{HCl}$. Zat kimia ini dibeli dari Merck dengan kualitas p.a. Selain itu, digunakan juga indikator $\mathrm{pH}$ Universal, aquades, aquabides, buah anggur, dll.

\section{Instrumentasi}

Alat yang digunakan diantaranya adalah neraca analitik, spektrofotometer UV-Vis, kamera digital dan alat-alat gelas. Alat gelas yang digunakan terlebih dahulu dicuci menggunakan detergen untuk menghilangkan kotoran organik seperti lemak, kemudian dibilas dengan air kran sampai bersih. Selanjutnya, alat gelas dicuci lagi menggunakan $\mathrm{HCl} 2 \mathrm{M}$ untuk menghilangkan kotoran anorganik seperti logam, dan dibilas dengan aquabides.

\section{Prosedur}

\section{Sintesis Nanopartikel Perak}

Buah Anggur yang digunakan sebagai bioreduktor dicuci hingga bersih dengan aquades, kemudian ditiriskan dari air cuciannya. Buah Anggur dibersihkan dari kulitnya lalu dipotongpotong dan ditimbang sebanyak 10 gram berat basah. Potongan buah dihaluskan dengan alu kemudian direbus pada suhu $80^{\circ} \mathrm{C}$ dengan $50 \mathrm{~mL}$ akuabides dalam Erlenmeyer selama 15 menit. Setelah itu, campuran kemudian didinginkan sampai suhu ruang. Ekstrak buah kemudian disaring menggunakan kertas saring Whatman (GE, UK) [12, 13].

Larutan stok perak nitrat $(1 \mathrm{mM})$ dibuat dengan menimbang $85 \mathrm{mg}$ perak nitrat yang kemudian dilarutkan dalam labu ukur $500 \mathrm{~mL}$ dan ditambahkan air (aquabides) sampai tanda batas, lalu dikocok sampai perak nitrat larut sempurna.

Sintesis NPP dilakukan dengan cara mereaksikan prekursor perak nitrat dengan ekstrak buah anggur dengan perbandingan volume 2:1, kemudian campuran dijemur di bawah sinar matahari. Pembentukan NPP diamati secara visual berdasarkan perubahan warnanya, dan diukur absorbansinya dengan spektrometer UV-Vis pada lambda 280-700 nm. Kestabilan NPP yang terbentuk diamati pada waktu 15, 30, 45, 60 menit, 2, 3, 24 jam, 2, 7 hari dengan diamati setiap hari pada waktu yang sama. Hasil biosintesis NPP yang paling optimum dari beberapa parameter akan digunakan untuk analisis deteksi ion logam merkuri secara kolorimetri [14].

\section{HASIL DAN PEMBAHASAN}

\section{Sintesis Nanopartikel Perak dan Aplikasinya}

NPP disintesis dengan cara mencampurkan perak nitrat $(1 \mathrm{mM})$ dengan ekstrak anggur. Proses ekstraksi buah anggur dilakukan pada suhu $80^{\circ} \mathrm{C}$. Pemilihan suhu rendah ini dimaksudkan agar senyawa aktif dalam buah anggur dapat larut dalam air tetapi tidak rusak karena panas dari proses perebusan. NPP yang terbentuk dari pencampuran ekstrak anggur dan $\mathrm{AgNO}_{3} 1 \mathrm{mM}$ dengan perbandingan volume 2:1 dicirikan dengan adanya pergantian warna campuran dari bening menjadi coklat kekuningan. Perubahan ini terbentuk saat campuran didiamkan di bawah sinar matahari. Sinar matahari berfungsi sebagai energi eksternal untuk mempercepat reaksi reduksi oksidasi pembentukan NPP.

Pembentukan NPP menggunakan ekstrak anggur ini memanfaatkan senyawa aktif fenolik 
dan vitamin $\mathrm{C}$ yang banyak terkandung pada ekstrak buah anggur. Nanopartikel perak $\left(\mathrm{Ag}^{0}\right)$ terbentuk karena reaksi reduksi ion $\mathrm{Ag}(\mathrm{I})$ yang ada pada larutan. Gugus fungsi dari senyawa yang terkandung pada ekstrak buah anggur bereaksi dengan cara memberikan elektron $\mathrm{ke}$ ion $\mathrm{Ag}(\mathrm{I})$ untuk membuat nanopartikel perak. NPP yang terbentuk memiliki absorbansi maksimum pada panjang gelombang $420 \mathrm{~nm}$. Setelah dilakukan uji keselektifan terhadap berbagai logam alkali, alkai tanah dan logam transisi, NPP yang terbentuk ternyata selektif hanya pada ion merkuri (II), ditandai dengan adanya perubahan warna NPP menjadi bening. Kurva hilangnya pita serapan pada saat penambahan berbagai konsentrasi ion $\mathrm{Hg}^{2+}$ pada NPP dapat dilihat di Gambar 1. Pada saat konsentrasi $\mathrm{Hg}^{2+}$ yang ditambahkan melebihi 50 ppm, maka warna NPP mulai menjadi bening. Hal ini terjadi karena NPP dalam bentuk $\mathrm{Hg}^{0}$ telah dioksidasi oleh $\mathrm{Hg}^{2+}$ menjadi ion $\mathrm{Ag}^{+}$kembali.

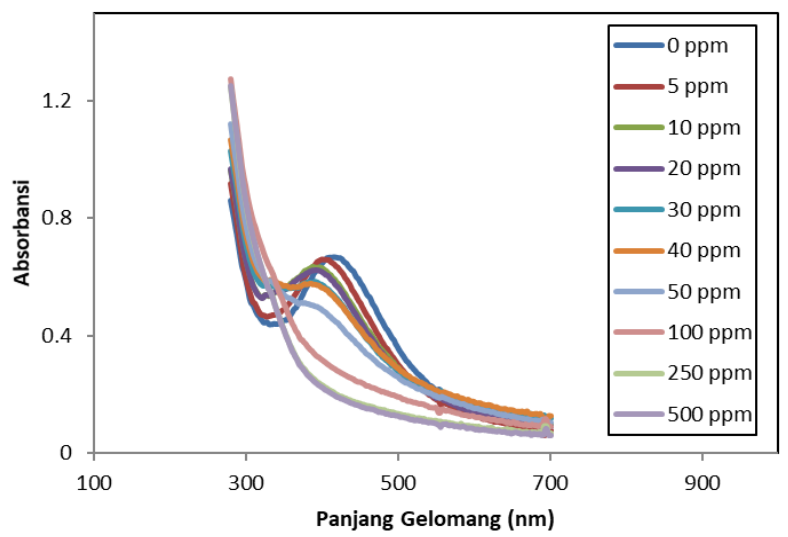

Gambar 1. Kurva hilangnya puncak serapan seiring dengan penambahan ion $\mathrm{Hg}^{2+}$.

\section{Analisis Ion Hg Secara Citra Digital}

Analisis kuantitatif ion $\mathrm{Hg}$ secara citra digital dilakukan dengan cara mengolah komponen warna dari NPP yang ditambahkan larutan $\mathrm{Hg}$. Citra digital diperoleh menggunakan kamera DSLR Canon EOS 30 D. Komponen warna RGB (Red Green Blue) dari NPP diperoleh dengan cara mengolah citra digital yang telah didapatkan. Untuk memilih bagian citra digital yang baik, foto di-crop menggunakan program Photoshop CS6. Pengambilan citra digital dilakukan pada waktu dan tempat yang sama untuk meminimalkan perbedaan serta digunakan ministudio untuk meminimalkan gangguan cahaya dari luar. Citra digital dari NPP yang ditambahkan larutan standar $\mathrm{Hg}$ pada berbagai konsentrasi ditampilkan pada Gambar 2.

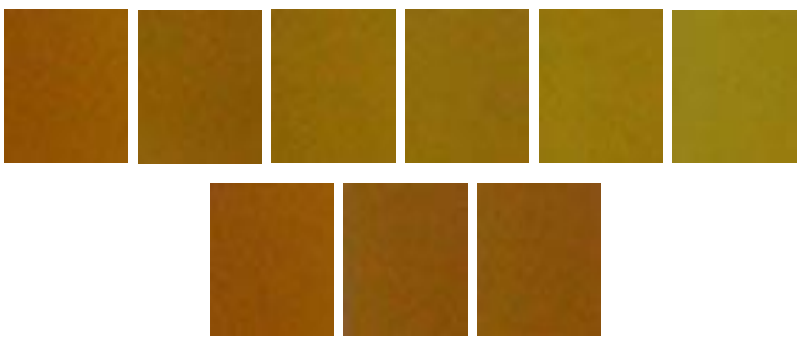

Gambar 2. Citra digital NPP + Ion $\mathrm{Hg}(0,10,20,30$, 40, 50 ppm) di bagian atas, dan sampel S1, S2, S3 di bagian bawah.

Untuk mendapatkan nilai masing-masing komponen warna RGB dari citra digital, digunakan program MATLAB R2010b. Nilai komponen warna RGB NPP + ion Hg dan sampel ditampilkan pada Tabel 1.

Tabel 1. Nilai komponen warna RGB standar NPP + ion Hg dan sampel.

\begin{tabular}{cccc}
\hline$[\mathrm{Hg}] \mathrm{ppm}$ & $\mathrm{R}$ & $\mathrm{G}$ & $\mathrm{B}$ \\
\hline 0 & 146,97 & 84,98 & 3,92 \\
10 & 141 & 96 & 5 \\
20 & 144 & 101 & 7 \\
30 & 138 & 105 & 10 \\
40 & 146 & 117 & 15 \\
50 & 150,21 & 128,76 & 19,76 \\
\hline Sampel 1 & 145,52 & 82,49 & 3,46 \\
Sampel 2 & 147,36 & 85,71 & 3,68 \\
Sampel 3 & 136,91 & 84,23 & 4,62 \\
\hline
\end{tabular}

Nilai komponen warna RGB ini akan diolah lebih lanjut dalam analisis kuantitatif ion $\mathrm{Hg}$ secara citra digital. Selanjutnya, nilai komponen warna RGB dikonversi menjadi intensitas RGB. Untuk mendapatkan nilai intensitas RGB digunakan persamaan Lambert Beer berikut:

$A=\log \frac{I_{0}}{I_{t}}$

A adalah intensitas RGB, $I_{0}$ adalah nilai komponen warna blanko dan $I_{t}$ adalah nilai komponen warna masing-masing ion standar $\mathrm{Hg}$. Data intensitas RGB ini selanjutnya diplotkan pada kurva kalibrasi antara konsentrasi ion $\mathrm{Hg}$ terhadap intensitas RGB. Kurva kalibrasi konsentrasi terhadap intensitas RGB seperti pada Gambar 3.

Gambar 3 menunjukkan bahwa komponen warna yang paling sensitif perubahannya yaitu komponen warna B (Biru) karena memiliki kemiringan lebih besar dari pada komponen warna $\mathrm{G}$ dan komponen warna R. Hal ini juga diperkuat 
dengan kelinierannya yang paling baik $\left(\mathrm{R}^{2}=\right.$ 0,9926).

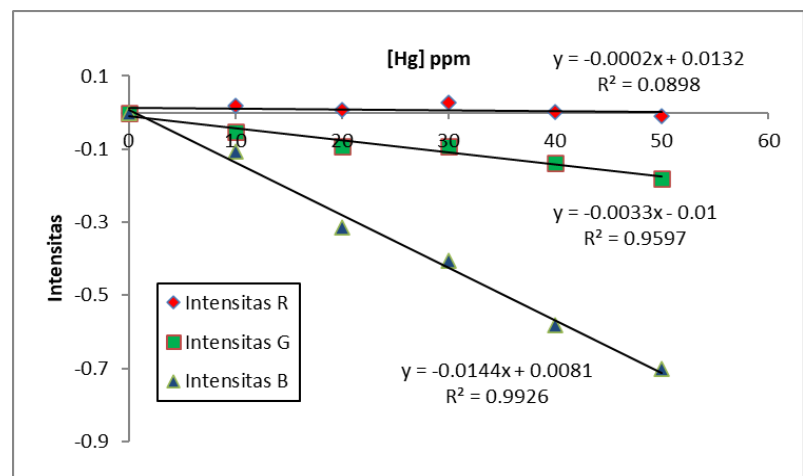

Gambar 3. Kurva kalibrasi konsentrasi ion merkuri terhadap intensitas R, Intensitas G, Intensitas B

Selanjutnya, teknik perhitungan Simple Linear Regression (SLR), yang menggunakan komponen warna paling sensitif sebagai patokan untuk mencari konsentrasi ion dan konsentrasi sampel dari Gambar $\mathbf{3}$ tersebut. Penentuan konsentrasi ion standar merkuri dan sampel menggunakan persamaan dari komponen warna $\mathrm{B}$, dengan cara pemanfaatan persamaan linier yang diperolehnya. Persamaan linier ini kemudian diubah menjadi:

$X=\frac{(Y-c)}{m}$

Nilai $\mathrm{X}$ (konsentrasi sampel) dapat ditentukan. dengan memasukkan nilai $\mathrm{Y}$ (Absorbansi G) dari sampel, c adalah intersep dan $m$ adalah gradien.

Teknik perhitungan kedua yang digunakan adalah Multiple Linear Regression (MLR). Penggunaan teknik perhitungan MLR ini memperhitungan semua komponen warna karena semua warna diserap oleh NPP dan sampel hanya saja intensitas serapannya berbeda. Analisis regresi MLR dilakukan menggunakan Software Minitab 16 dan Microsoft Excel 2010, sehingga persamaan yang memperhitungkan semua komponen warna dapat diperoleh. Persamaan MLR yang diperoleh adalah $\mathrm{C}=0,011+57,4 \mathrm{R}-75,2 \mathrm{G}-52,0 \mathrm{~B}$, dengan persamaan ini dapat dihitung konsentrasi merkuri pada sampel.

Kekakuratan dari metode citra digital ditentukan dengan membandingkan hasil pengukurannya dengan metode Spektrofotometri UV-Vis. Keakuratan metode citra digital (SLR dan MLR) ditentukan dengan cara membandingkan hasil analisis larutan standar menggunakan metode citra digital tersebut dengan metode yang selama ini sudah diakui kemampuannya yaitu metode Spektrofotometri UV-Vis. Perbandingan hasil penentuan konsentrasi larutan standar $\mathrm{Hg}$ dari metode citra digital dibandingkan dengan Spektrofotometri UV-Vis bisa diamati pada Tabel 2.

Tabel 2. Penentuan konsentrasi ion Standar Hg metode Citra digital dengan Spektrofotometri UV-Vis

\begin{tabular}{cccc}
\hline$[\mathrm{Hg}] \mathrm{ppm}$ & SLR & MLR & UV-Vis \\
\hline 0 & 1,547945 & 0,011 & 0 \\
10 & 8,786571 & 10,52249 & 10,565 \\
20 & 18,79534 & 19,25449 & 21,271 \\
30 & 29,40506 & 29,63881 & 28,682 \\
40 & 41,46611 & 40,9249 & 39,035 \\
50 & 49,66444 & 49,56837 & 51,035 \\
\hline
\end{tabular}

Perbandingan akurasi citra digital dengan spektrofotometri UV-Vis ditentukan dengan cara memplotkan konsentrasi ion standar $\mathrm{Hg}$ metode Spektrofotometri UV-Vis pada sumbu y dan konsentrasi ion standar metode citra digital menggunakan perhitungan SLR dan MLR pada sumbu $x$. Hasil keakuratannya dilihat dari kelinieran metode citra digital menggunakan perhitungan SLR dan MLR terhadap spektrofotometri UV-Vis pada Gambar 4.

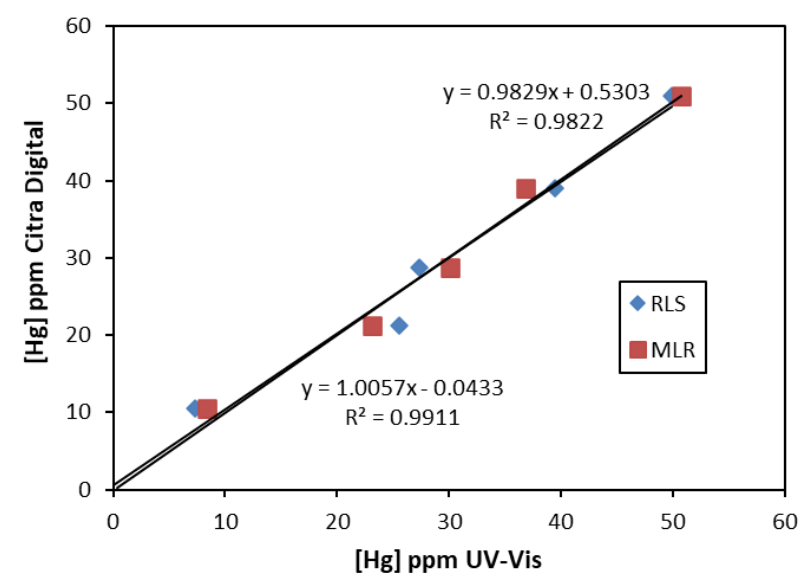

Gambar 4. Perbandingan keakuratan metode Citra digital dengan UV-Vis.

Perbandingan konsentrasi larutan standar $\mathrm{Hg}$ dari metode citra digital dengan metode spektrometri UV-Vis menghasilkan nilai $\mathrm{R}^{2}$ untuk SLR sebesar 0,9879 dan nilai $\mathrm{R}^{2}$ untuk MLR sebesar 0,9938. Nilai ini menunjukkan hubungan yang linier antara citra digital (SLR) dan citra digital (MLR) dengan UV-Vis. Hubungan yang linier ini menunjukkan bahwa metode citra digital dengan perhitungan SLR dan MLR bisa digunakan untuk

analisis kuantitatif ion $\mathrm{Hg}$ menggunakan NPP. Keakuratan metode citra digital 
menggunakan perhitungan SLR terhadap spektrofotometri adalah $98,22 \%$ dan akurasi metode citra digital memanfaatkan perhitungan MLR terhadap spektrometri UV-Vis adalah 99,11 $\%$. Hal ini menunjukkan bahwa metode citra digital memiliki akurasi yang tinggi dalam analisis kuantitatif logam berat menggunakan NPP jika dibandingkan terhadap metode spektrofotometri UV-Vis.

Hasil dari aplikasi metode yang kami kembangkan ini menunjukkan bahwa konsentrasi ion $\mathrm{Hg}$ pada sampel air sungai Muara Bangkahulu, Air Danau UNIB, dan Air keran Dekanat FKIP UNIB tidak terukur karena kadarnya yang sangat kecil atau di bawah limit deteksi (LOD) metode citra digital dan UV-Vis yaitu 0,11 ppm. Batas deteksi citra digital bisa ditingkatkan dengan cara menggunakan wadah sampel yang memiliki permukaan flat, seperti kuvet [15]. Berdasarkan hasil penelitian ini disimpulkan bahwa air lingkungan tersebut tidak terkontaminasi oleh merkuri sesuai dengan peraturan Permenkes RI nomor 57 tahun 2016 [16].

\section{SIMPULAN}

Pada penelitian ini telah berhasil dibuat nanopartikel perak dengan memanfaatkan reduktor alami dari ekstrak buah anggur. NPP yang dibuat ini kemudian digunakan untuk mendeteksi kandungan ion merkuri pada sampel lingkungan secara citra digital menggunakan telepon genggam atau kamera digital, sebagai alat alternatif yang lebih portable, ekonomis, dan ramah lingkungan dibandingkan dengan alat yang biasa digunakan, seperti voltammeter, spektrofotometer UV-Vis, AAS dan ICP-AES. Metode citra digital dan nanopartikel perak ini dapat digunakan untuk menganalisis logam berat merkuri dengan hasil yang memuaskan, ditandai dengan tingginya keakuratan metode citra digital dibandingkan dengan Spektrofotometri UV-Vis, yaitu sebesar 98,22\% untuk SLR dan 99,11\% untuk MLR.

\section{UCAPAN TERIMA KASIH}

Penulis mengucapkan terimakasih kepada DRPM - Kemenristekdikti, Republik Indonesia yang telah mendanai penelitian ini melalui kontrak nomor 7/E/KPT/2019.

\section{REFERENSI}

[1] T.W. Clarkson, "The toxicology of mercury" Critical reviews in clinical laboratory sciences, vol. 34, no. 4, pp. 369-403, 1997.

[2] N.H. Tarras-Wahlberg, A. Flachier, S. N.
Lane, and O. Sangfors. "Environmental impacts and metal exposure of aquatic ecosystems in rivers contaminated by small scale gold mining: the Puyango River basin, southern Ecuador", Science of the Total Environment, vol. 278, no. 1-3, pp. 239-261, 2001.

[3] S.A. El-Safty, M.A. Shenashen, and S.A. ElSafty, "Mercury-ion Optical Sensors", TrAC Trends in Analytical Chemistry, vol. 38, pp. 98-115, 2012.

[4] Y. Hong, Y. Kim, and K. Lee, "Methylmercury Exposure and Health Effects", Journal of Preventive Medicine and Public Health, vol. 45, no. 6, pp. 353-363, 2012.

[5] R.W. Siegler, D.W. Nierenberg, and W.F. Hickey, "Fatal Poisoning from Liquid Dimethylmercury: A Neuropathologic Study", Human Pathology, vol. 30, no. 6, pp. 720-723, 1999.

[6] M. Harada, "Minamata Disease: Methylmercury Poisoning in Japan Caused by Environmental Pollution", Critical Reviews in Toxicology, vol. 25, no. 1, pp.1-24, 1995.

[7] L. Järup, "Hazards of Heavy Metal Contamination", British Medial Bulletin, vol. 68, no. 1, pp. 167-182, 2003.

[8] Z.C. Castilhos, S. Rodrigues-Filho, A.P.C. Rodrigues, R.C. Villas-Bôas, S. Siegel, M.M. Veiga, and C. Beinhoff, "Mercury contamination in fish from gold mining areas in Indonesia and human health risk assessment", Science of Total Environment, vol. 368, no.1, pp. 320-325, 2006.

[9] N. Pourreza and K. Ghanemi, K. "Determination of Mercury in Water and Fish Samples by Cold Vapor Atomic Absorption Spectrometry After Solid Phase Extraction on Agar Modified with 2Mercaptobenzimidazole", Journal of Hazardous Materials, vol. 161, no. 2-3, pp. 982-987, 2009.

[10] L. Husáková, A. Bobrowski, J. Srámková, A. Królicka, and K. Vytras, "Catalytic Adsorptive Stripping Voltammetry Versus Electrothermal Atomic Absorption Spectrometry in The Determination of Trace Cobalt and Chromium in Human Urine", Talanta, vol. 66, no. 4, pp. 999-1004, 2005.

[11] G. Jarzynska and J. Falandysz, "The Determination of Mercury in Mushrooms by CV-AAS and ICP-AES Techniques", Journal of Environmental Science and Health, Part A. Toxic/Hazardous Substances and Environmental Engineering, vol. 46, no. 6, pp. 569-573, 2011. 
[12] M. L. Firdaus, I. Fitriani, S. Wyantuti, Y.W. Hartati, R. Khaydarov, J. A. McAlister, H. Obata, and T. Gamo, "Colorimetric detection of mercury(II) ion in aqueous solution using silver nanoparticles", Analytical Sciences, vol. 33, no. 7, pp. 831-837, 2017.

[13] M. L. Firdaus, S. Andriana, W. Alwi, E. Swistoro, A. Ruyani, and A. Sundaryono, "Green synthesis of silver nanoparticles using Carica Papaya fruit extract under sunlight irradiation and their colorimetric detection of mercury ions", Journal of Physics: Conference Series, vol. 817, no. 1, 2017.
[14] M. L. Firdaus, I. Fitriani, S. Wyantuti, Y.W. Hartati, R. Khaydarov, J. A. McAlister, H. Obata, and T. Gamo, "Colorimetric detection of mercury(II) ion in aqueous solution using silver nanoparticles", Analytical Sciences, vol. 33, no. 7, pp. 831-837, 2017.

[15] M. L. Firdaus, A. Aprian, N. Meileza, M. Hitsmi, R. Elvia, L. Rahmidar, and R. Khaydarov, "Smartphone Coupled with a Paper-Based Colorimetric Device for Sensitive and Portable Mercury Ion Sensing", Chemosensors, vol. 7, no. 2, pp. 25, 2019.

[16] Permenkes RI No. 492/Menkes/Per/IV/ 2010, Persyaratan Kualitas Air Minum, Jakarta, 2010. 